\title{
Applied WEEE pre-treatment methods: Opportunities to maximizing the recovery of critical metals
}

\author{
Batinic B. ${ }^{1,}{ }^{*}$, Vaccari M. ${ }^{2}$, Savvilotidou V. ${ }^{3}$, Kousaiti A. ${ }^{3}$, Gidarakos E. ${ }^{3}$, Marinkovic T. ${ }^{1}$ and Fiore S. ${ }^{4}$ \\ ${ }^{1}$ University of Novi Sad, Faculty of Technical Sciences, Department of Environmental Engineering and Occupational Safety and Health, \\ Trg Dositeja Obradovica 6, 21000 Novi Sad, Serbia \\ ${ }^{2}$ University of Brescia, Department of Civil, Environmental, Architectural Engineering and Mathematics, Via Branze 43, 25123 Brescia, \\ Italy \\ ${ }^{3}$ Technical University of Crete, School of Environmental Engineering, University Campus, P.C. 73100, Chania, Crete, Greece \\ ${ }^{4}$ DIATI (Department of Engineering for Environment, Land and Infrastructures), Politecnico di Torino, corso Duca degli Abruzzi 24,10129 \\ Torino, Italy
}

Received: 17/01/2018, Accepted: 14/04/2018, Available online: 26/09/2018

*to whom all correspondence should be addressed: e-mail: bojanbatinic@uns.ac.rs

https://doi.org/10.30955/gnj.002589

\begin{abstract}
WEEE is a fast-growing waste stream that includes potentially hazardous substances, but also valuable secondary raw materials, which can be recovered by adequate recycling and recovery treatment. In the last years, the research interest has moved from the conventional recycling (recovery of ferrous and non-ferrous metals, plastic, glass and other "mass relevant" fractions presented in WEEE), to the innovational recycling, aimed to recover trace elements, such as critical metals (CMs) and rare earth elements (REEs). Currently, the majority of CMs and REEs are lost during the pre-treatment processes. In this paper, an overview of the most relevant e-waste categories and products in terms of CMs and REEs presence, a description of currently applied pre-treatment methods and fate of the observed group of metals during pre-processing phase, as well as general recommendation in order to avoid losses of CMs and REEs within the WEEE treatment chain, are elaborated.
\end{abstract}

Keywords: Electronic waste, physical separation, secondary resources, rare earth elements.

\section{Introduction}

According to the European Commission Report (EC, 2017), 27 raw materials, which have strategic importance for EU manufacturing industry, high economic importance and high supply risk, were identified as critical raw materials (CRMs) at EU level. EU Raw Materials Initiative started in 2008 to define their secure, sustainable and affordable supply. The CRMs list, updated every 3 years, is a crucial element of this Initiative. EU interest on CRMs is focused on the support of technical solutions that could alleviate EU dependence on import from developing countries. Within Report (EC, 2017), "Import reliance rate" calculated as a ratio between net imports of specific CRM in EU countries and its production on the EU level, shows that for 14 materials of 27 , its value is equal, or nearly $100 \%$. On the other hand, "Recycling input rate" which indicates the ratio of recycling and EU demand of a given critical raw material, is only up to $1 \%$ for 17 observed CRMs (Figure 1).

Moreover, EU Raw Materials Initiative is fully coherent with EU strategy about transitioning towards a low-carbon, resource efficient and more circular economy. In line with that, WEEE is recognized as a very important secondary resource of CRMs (Chancerel et al., 2013; Marra et al., 2015; Diaz et al., 2015). In particular, metals from the list of critical raw materials, such as gallium, tantalum, indium, cobalt, beryllium, tungsten, etc., which can be found in WEEE are therefore defined as a critical metals (CMs). Besides, a specific group of critical metals like europium, terbium, yttrium, cerium, gadolinium, neodymium, and others, also contained in WEEE, are designated as a rare earth elements (REEs).

In addition, base metals (iron, steel, copper, aluminum) and precious metals (gold, silver, palladium, platinum) as the most dominant metals in WEEE, even if not CMs, are very important for EU economy as they are needed in large amounts as starting point of manufacturing chains. Therefore, it is evidently that the contribute that WEEE may give within a circular economy approach plays a primary role.

In order to separate components that contain valuable materials or to upgrade relevant fractions prior to recycling process, it is crucial to focus on increasing the collection rates and mainly on optimizing the operating conditions of pre-processing stage in WEEE recycling chain. In fact, the recovery of a specific material from end-of-life e-waste input stream increases with decreasing of impurities in the final material (Chancerel et al., 2009). Even the key role is the determination of the obsolete product characteristics, the main defect still occurs at the pre-treatment stage (Meskers et al., 2009), which includes liberation through manual dismantling, 
and/or shredding and manual and/or mechanical separation (Bigum, 2012), and result overall the reduction of the recycling efficiency. In order to enhance critical metals recovery, it is necessary to develop specialized systematic approaches in those certain e-waste streams that are composed by higher concentrations of CMs.

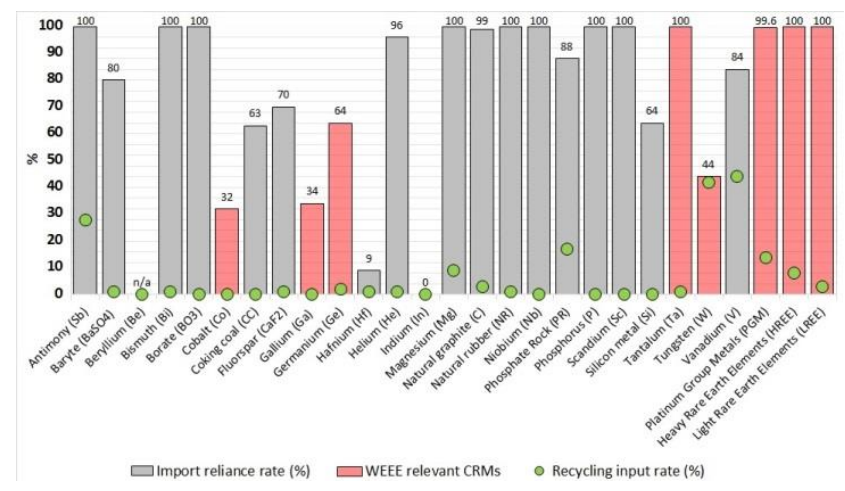

Figure 1. Reliance on import and recycling input rates for selected CRMs on EU level (data used from EC, 2017)

Therefore, a compromise between the quality and quantity of grade-recovery fraction has to be carried out to minimize the losses of valuable metals and the distribution of critical metals over the outputs of the WEEE preprocessing stage. The objective of this paper is to present a succinct overview on the e-waste categories and products in terms of CMs and REEs, the currently applied pre-treatment processes, and the fate of the $\mathrm{CMs} / \mathrm{REEs}$ during pre-treatment phase.

\section{Relevant e-waste categories and products in terms of CMs/REEs}

The environmental impact, the exploitation of resources and the global regulations, but mainly the values contained in e-waste become the main driving forces for the recovery of critical and rare earth metals from e-waste. Not only the recycling of e-waste leads to conservation of primary ores, saving energy and reducing carbon footprint, but it should be also noticed that the amount of CMs in WEEE is comparable, and in some cases even significantly higher to the content of precious and critical metals in mineral ores (Işıldar et al., 2017), which leads to the fact that WEEE becomes important resource within "urban mining" concept.

Since one of the most important parameter for pretreating e-waste without losing CMs is to know in advance their initial concentrations, the content of WEEE in terms of CMs is presented in Table 1. This is essential in order to classify the most important or most "mass relevant to CM" categories of WEEE included in Directive's catalogue.

Products that include IT and telecommunication equipment, consumer equipment (i.e., category 3 and 4 according to WEEE Directive 2012/19/EU), as well as lighting equipment (category 5 ), are the richest of precious metals and rare earth elements (Bigum, 2012; Tsamis and Coyne, 2015). High-grade electronic scrap such as automotive catalysts, batteries, circuit boards, mobile phones and MP3 players need to be separated prior to mechanical pre-processing to prevent irrecoverable losses
(Gunn, 2014). For low-grade electronic scrap such as small domestic appliances and audio-visual equipment, a coarse size reduction is needed prior the removal of circuit board fractions. In addition, high-strength magnets used in motors and hard disk drivers may represent an important source in terms of REEs because their concentration within them is significant high (Gunn, 2014).

Focusing on printed circuit boards (PCBs), these contain polymers, ceramics as well as metals. Specifically, the metal content is around $28 \%$ (consisting of copper: 10-20\%, lead: $1-5 \%$, nickel: $1-3 \%$ ). Some precious metals are also present (in decreasing order: silver, platinum metals like palladium, gold, to a total of $\approx 0.3-0.4 \%$ ) (Veit et al., 2005). Metals such as gallium, indium, titanium, germanium, arsenic, selenium and tellurium can be found in lower content values in integrated circuits and semiconductors (Işıldar et al., 2017).

Similarly, regarding batteries, mercury is located in the dry batteries and cadmium in the $\mathrm{Ni}-\mathrm{Cd}$ batteries (Yue-qing and Guo-jian, 2004), but also cobalt is found in them (Sommer et al., 2015).

According to the scientific community, REEs are significantly located into permanent magnets (particularly neodymium and praseodymium), nickel-hydride batteries and fluorescent lamps (Binnemans et al., 2013; Hobohm et al., 2016; Işıldar et al., 2017). However, the low concentrations of rare elements, the high market price, the complex components and the heterogeneous combination of materials (Charles et al., 2017; Marra et al., 2015; Savvilotidou et al., 2014) make their recovery difficult, but also challenging (Dias et al., 2016).

\section{Description of currently applied pre-treatment processes}

For efficient recycling of e-waste, pre-treatment as a combination of manual (dismantling and separation) and physical processes (size reduction and different physical separation) represent a first and indispensable step. The main task of WEEE pre-processing is to ensure that liberated materials enter the appropriate recovery processes (Ueberschaar et al., 2017a). Before final metal recovery in hydro and/or pyro metallurgical processing, appropriate pre-treatment steps, are crucial.

Currently applied pre-treatment methods are customized for efficient separation and recovery of "mass relevant" fraction in e-waste, mostly metals (Fe, steel, $\mathrm{Ni}, \mathrm{Al}, \mathrm{Cu}$, brass), but also non-metallic fractions, like plastic, glass, rubber, wood, textile etc. Thus, the majority of CMs and REEs are lost, as they stay coupled with dominant metal output fractions, or end up in the dust from the process. This disables possibility for their recovery in hydrometallurgical or pyrometallurgical process, as end-processing steps (Chancerel et al., 2009). In general, pre-treatment phase includes:

- Manually disassembly/dismantling

- Mechanical treatment processes 
- Combination of manual and mechanical preprocessing

Manually dismantling phase is crucial to ensure removal of all relevant hazardous and/or valuable components such as: casings, external cables, cathode ray tubes (CRTs), PCBs, batteries, etc., defined in Annex VII of the WEEE Directive 2012/19, while this step becomes labor intensive (Zhang and Forssberg, 1998).
As shown in Figure 2, manual sorting and dismantling are usually followed by a traditional recycling processes, where metals and materials contained in WEEE are liberated and separated based on their specific physical characteristics such as weight, size, shape, density, and electrical and magnetic characteristics (Oliveira et al., 2012).

Table 1. Precious, critical and rare earth metals content in high-grade e-waste products

\begin{tabular}{|c|c|c|c|c|}
\hline Category/type of WEEE & $\begin{array}{l}\text { Element } \\
\text { category }\end{array}$ & Element & $\begin{array}{c}\text { Average } \\
\text { content (wt\%) }\end{array}$ & References \\
\hline \multicolumn{5}{|l|}{ 1. LARGE HOUSEHOLD APPLIANCES } \\
\hline \multirow[t]{4}{*}{ PCBs } & \multirow{3}{*}{ Precious metals } & $\mathrm{Ag}$ & $0.1 \mathrm{E}-01$ & \multirow[t]{3}{*}{ D’Adamo et al., 2016} \\
\hline & & $\mathrm{Au}$ & $0.3 \mathrm{E}-02$ & \\
\hline & & $\mathrm{Pd}$ & $0.3 \mathrm{E}-02$ & \\
\hline & Critical metals & $\mathrm{Sb}$ & $0.8 \mathrm{E}-01$ & D'Adamo et al., 2016 \\
\hline \multicolumn{5}{|l|}{ 2. SMALL HOUSEHOLD APPLIANCES } \\
\hline & \multirow{3}{*}{ Precious metals } & $\mathrm{Ag}$ & $2.2 \mathrm{E}-04$ & \multirow[t]{3}{*}{ Huismann et al., 2007} \\
\hline & & $\mathrm{Au}$ & $2.0 \mathrm{E}-05$ & \\
\hline & & $\mathrm{Pd}$ & $1.2 \mathrm{E}-05$ & \\
\hline \multicolumn{5}{|l|}{ 3. IT \& TELECOMMUNICATION EQUIPMENT } \\
\hline Personal computers & Precious metals & $\mathrm{Ag}$ & $6.4 \mathrm{E}-02$ & Cui and Forssberg, 2007 \\
\hline \multirow{4}{*}{ Liquid-Crystal Display monitors } & \multirow{4}{*}{ Precious metals } & $\mathrm{Au}$ & $2.3 \mathrm{E}-03$ & \multirow{3}{*}{ Bakas et al., 2016} \\
\hline & & $\mathrm{Ag}$ & 7.4E-03 & \\
\hline & & $\mathrm{Pd}$ & $6.1 \mathrm{E}-04$ & \\
\hline & & In & $5.3 \mathrm{E}-02$ & Savvilotidou et al., 2015 \\
\hline Mobile phones & \multirow{3}{*}{ Precious metals } & $\mathrm{Pd}$ & $0.4 \mathrm{E}-02$ & \multirow{5}{*}{ Bakas et al., 2016} \\
\hline & & $\mathrm{Au}$ & $0.9 \mathrm{E}-02$ & \\
\hline & & $\mathrm{Ag}$ & $0.9 \mathrm{E}-02$ & \\
\hline & \multirow{2}{*}{ Critical metals } & Co & $0.2 \mathrm{E}+01$ & \\
\hline & & $\mathrm{Be}$ & $0.1 \mathrm{E}-02$ & \\
\hline \multirow{6}{*}{ PCBs (from laptops and mobile phones) } & \multirow{4}{*}{ Precious metals } & $\mathrm{Ag}$ & $1.3 \mathrm{E}-01$ & \multirow{4}{*}{ Wang and Gaustad, 2012} \\
\hline & & $\mathrm{Au}$ & $3.6 \mathrm{E}-02$ & \\
\hline & & $\mathrm{Pd}$ & $1.2 \mathrm{E}-02$ & \\
\hline & & $\mathrm{Pt}$ & $2.2 \mathrm{E}-03$ & \\
\hline & \multirow[t]{2}{*}{ Critical metals } & $\mathrm{Ga}$ & $3.5 \mathrm{E}-03$ & \multirow{2}{*}{ Wang and Gaustad, 2012} \\
\hline & & $\mathrm{Ta}$ & 1.7E-02 & \\
\hline \multicolumn{5}{|c|}{ 4. CONSUMER EQUIPMENT AND PHOTOVOLTAIC PANELS } \\
\hline \multirow{3}{*}{ Photovoltaic modules } & Precious metals & $\mathrm{Ag}$ & $0.6 \mathrm{E}-01$ & Dias et al., 2016 \\
\hline & \multirow{2}{*}{ Critical metals } & $\ln$ & $7.9 \mathrm{E}-03$ & \multirow{2}{*}{ Savvilotidou et al., 2017} \\
\hline & & $\mathrm{Ga}$ & $1.5 \mathrm{E}-02$ & \\
\hline & & $\mathrm{Ag}$ & $0.2 \mathrm{E}-02$ & \\
\hline TV sets & Precious metals & $\mathrm{Au}$ & $0.7 \mathrm{E}-02$ & Cui and Forssberg, 2007 \\
\hline & Critical metals & W & $9.1 \mathrm{E}-03$ & Bakas et al., 2016 \\
\hline PCB from cathode ray tubes (CRTs) TV & Procious motalc & $\mathrm{Ag}$ & $2.8 \mathrm{E}-02$ & Cui and Eorcchera 2007 \\
\hline monitors & Precious metals & $\mathrm{Au}$ & $1.1 \mathrm{E}-02$ & Cul and Forssberg, $200 /$ \\
\hline 5. LIGHTING EQUIPMENT & & & & \\
\hline & & La & $6.0 \mathrm{E}-01$ & \\
\hline Fluorescent lamps & & $\mathrm{Ce}$ & $6.0 \mathrm{E}-01$ & Sun et al., 2016 \\
\hline & & $\mathrm{Y}$ & $0.8 \mathrm{E}+01$ & \\
\hline Fluorescent powders (CRTs) & & $\mathrm{Y}$ & $7.8 \mathrm{E}-04$ & Innocenzi et al., 2013 \\
\hline & & La & $0.8 \mathrm{E}-01$ & \\
\hline & & $\mathrm{Ce}$ & $1.1 \mathrm{E}-01$ & \\
\hline Dhornhors 120 & Rare earth & $\mathrm{Eu}$ & $0.5 \mathrm{E}-01$ & Dinnomans ot 2012 \\
\hline Phosphors & & $\mathrm{Gd}$ & $0.2 \mathrm{E}-01$ & Bınnemans et al., 2013 \\
\hline & & $\mathrm{Tb}$ & $0.5 \mathrm{E}-01$ & \\
\hline & & $Y$ & $6.9 \mathrm{E}-01$ & \\
\hline
\end{tabular}




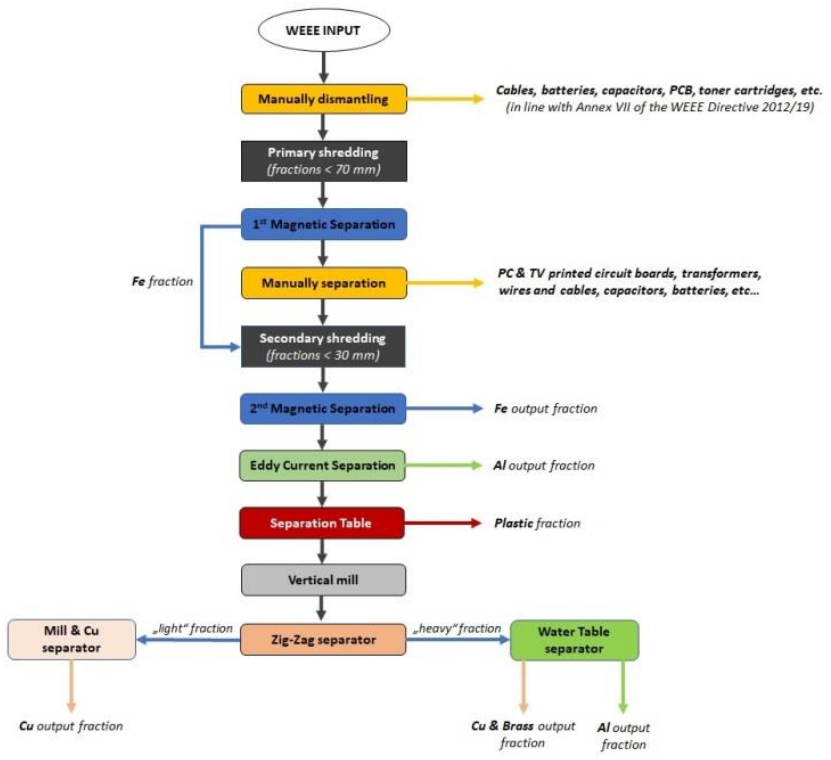

Figure 2. General scheme of applied processes in WEEE pretreatment stage

Typically, mechanical pre-treatment starts with size reduction, using shredding or crushing process. Depending on the needed size of output material, several shredding/grinding processes are used during the whole mechanical pre-treatment stage. After size reduction, separation of a group of ferrous metals (Fe, steel, $\mathrm{Ni}$, etc.) is performed by magnetic separation, where low intensity magnetic drum separators are widely used for this purpose. This step is usually followed by separation of non-ferrous metals flow ( $\mathrm{Al}, \mathrm{Cu}$, etc.) from other materials (mainly plastic, glass, etc.), by using some of the electric conductivity-based separation techniques. Eddy current separation and corona electrostatic are the most commonly used in e-waste recycling processes, especially after strong permanent magnets, such as iron-boron-neodymium magnets, became available (Zhang and Forssberg, 1998).

Finally, based on the fact that every material particle in WEEE has a specific density, gravity concentration methods separate materials of different specific gravity by their relative movement in response to gravity. Gravity separation techniques include water or airflow tables, heavy media floating, sifting, etc. (Oliveira et al., 2012).

As an alternative or in combination with some of the described conventional mechanical pre-treatment processes, sensor and/or optical based sorting techniques can be also applied (Hageluken, 2006). Usually, sensor sorting can be used in the advanced stage of pre-treatment process, in order to further separate different types of plastics and possibly glass from the output stream. Menad et al. (2013) show that plastic can be efficiently separated from non-metallic fraction flow using sensor sorting devices. Through the performed characterization of samples from different recycling industries, it was concluded that recognition of plastic with IR (infrared) sensors is not applicable for black and coloured plastic fragments. However, sorting of coloured plastics in different polymer types can be efficiently done by fast NIR (Near Infra-Red) spectroscopy. Furthermore, flame retardants and other additives in plastic from WEEE (bromine, phosphor, antimony) can be identified with XRF device.

\section{The fate of $\mathrm{CMs}$ in pre-treatment processes}

Fully automated disassembly is currently not technically feasible and not expected to become economically viable in coming years (Duflou et al., 2008). Currently, the greatest need for the technical optimization of recycling is to ameliorate manual disassembly during the pre-treatment stage. Besides, Buchert et al. (2012) show that the general standard practice of shredding whole devices, in Germany, leads to considerable losses of CMs in particular precious metals - which cannot be compensated by the downstream sorting and refining processes. To improve the recovery of precious and other critical metals, it is essential to manually remove the components containing important raw materials such as PCBs and batteries and feed these components separately to recycling facilities. Based on elemental material flow analysis Ueberschaar et al. (2017a), concluded that in pre-sorting step due to battery removal, about $46 \%$ of cobalt and $38 \%$ of a group of REEs are separated from the input WEEE flow. High concentrations of cobalt and REEs (about 30\% and 60\%, respectively) were also found within ferrous metals fraction after use of magnet separator (Figure 3).

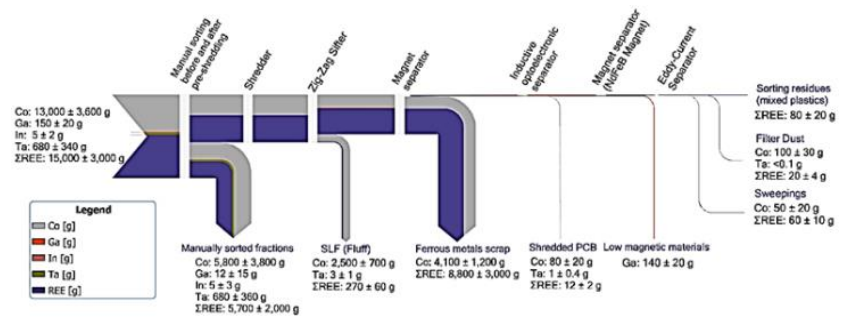

Figure 3. Mass balance of the cobalt, gallium, indium, tantalum and group of REEs during WEEE pre-processing stage (redrawn from Ueberschaar et al., 2017a)

In order to examine the losses of precious metals due to shredding of PCBs, Chancerel et al. (2009), through an industrial test, determined the difference in concentration between unshredded and preshredded PCBs. The results showed $7 \%$ less precious metals in the preshredded PCBs compared with the un-shredded PCBs. Furthermore, the difference between preshredded PCBs (size $<8 \mathrm{~mm}$ ) and shredded PCBs (size $<2.5 \mathrm{~mm}$ ) indicates $62 \%$ less precious metals in the shredded PCBs compared with the preshredded PCBs.

Ueberschaar et al. (2017b) show that the relatively small shares of gallium bearing components on PCBs or in light emitting diodes (LEDs) lead to a dilution with other materials in recycling processes used conventionally. Ending in the pyrometallurgical process for copper and precious metals refining, gallium is transferred as oxidized form to the slag. Thus, gallium rich components must be separated prior to any mechanical processing with other material. In particular, mobile phones and newly tablets 
are important gallium sources, bearing more than $40 \%$ of the total gallium loads in the IT and entertainment equipment.

On example of neodymium, Marra et al. (2015), demonstrated that about $90 \%$ of $\mathrm{Nd}$ is lost throughout conventional pre-treatment techniques, mainly ended up in the process air dust.

\section{Recommendation to avoid losses of CMs/REEs within the WEEE treatment chain}

In order to recover CMs from WEEE, some of the crucial improvements in steps that precede pre-treatment phase in overall recycling chain, includes:

- More reliable and transparent information about the content of CMs in the different equipment groups and their components

- Increase of the collection rates for all product groups that contain $\mathrm{CM}$

- Optimized structure and design of EEE products that facilitates manual disassembly and recycling processes.

With regard to WEEE pre-treatment phase, more particular recommendation and measures for avoiding losses of CMs and REEs are:

i Optimization of pre-treatment processes based on further improvement of manual disassembly and separation of target components in WEEE with high concentration of CMs. Besides removal of the WEEE components that are legally stipulated, parts of equipment such as batteries containing cobalt, neodymium hard disk magnets, small PCBs, etc. (Buchert et al., 2012), should be also removed and fed into a suitable recycling process.

ii Outputs from pre-treatment phase must be fractions with form and characteristics appropriate for end-processing facilities. More investments and further research should be focused on promising technologies for automatic recognition, sorting, and dismantling of WEEE, in order to recover CM from heterogenous WEEE flows, more efficiently (Buchert et al., 2012; Chancerel et al., 2010).

iii Quantitative targets for the recycling of WEEE are not formulated specifically in terms of material or components, but relate to the weight percent of the complete devices, which leads to negative incentives for the recovery of $\mathrm{CM}$. Therefore, revision of the WEEE Directive in terms of setting targets for the recycling rates for specific critical metals and/or product groups, is recommended (Buchert et al., 2012; Chancerel et al., 2010).

\section{Conclusion}

Currently, the worldwide recycling rate of critical metals from WEEE is negligible. Although pre-treatment methods can effectively separate mass-relevant metals like iron, aluminum and copper, CMs and REEs as a trace metals are practically completely lost throughout conventional techniques, mainly due to fact that these substances end up in a form of the output stream from which they cannot be recovered in final processing steps. Thus, it is obvious that adjustment of applied pre-treatment processes, in order to achieve adequate CM output stream for recovery, is needed. Measures such as enhancement of manual dismantling phase and separation of components in WEEE with high concentration of CMs, adjustment of pre-treatment process that enable appropriate output materials suitable for end-processing facilities, as well as amendment of the WEEE Directive and defining recycling targets based on specific material or components, represent the essential steps to avoid further losses of CMs from WEEE. However, providing the economic viability of the pre-treatment improvements, is one of the main prerequisite for successful implementation of aforementioned measures.

\section{Acknowledgment}

This research was carried out in the framework of the activities of the COST Action ES1407 - European network for innovative recovery strategies of rare earth and other critical metals from electric and electronic waste (ReCreew).

\section{References}

Bakas I.C., Herczeg M.C., Vea E.B.C., Fråne A.I., Youhanan L.I. and Baxter J.Ø. (2016). Critical Metals in Discarded Electronics: Mapping Recycling Potentials from Selected Waste Electronics in the Nordic Region. Nordic Council of Ministers.

Bigum M., Brogaard L. and Christensen T.H. (2012). Metal recovery from high-grade WEEE: a life cycle assessment. Journal of Hazardous Materials, 207, 8-14.

Binnemans K., Jones P.T., Blanpain B., Van Gerven T., Yang Y., Walton A. and Buchert M. (2013), Recycling of rare earths: a critical review, Journal of Cleaner Production, 51, 1-22.

Buchert M., Manhart A., Bleher D. and Pingel D. (2012). Recycling critical raw materials from waste electronic equipment. Freiburg: Öko-Institut eV, 49(0), 30-40.

Chancerel P., Bolland T. and Rotter V.S. (2010). Status of preprocessing of waste electrical and electronic equipment in Germany and its influence on the recovery of gold. Waste Management \& Research, 29(3), 309-17.

Chancerel P., Meskers C.E., Hagelüken C. and Rotter V.S. (2009). Assessment of precious metal flows during preprocessing of waste electrical and electronic equipment. Journal of Industrial Ecology, 13(5), 791-810.

Chancerel P., Rotter V.S., Ueberschaar M., Marwede M., Nissen N.F. and Lang K.-D. (2013). Data availability and the need for research to localize, quantify and recycle critical metals in information technology, telecommunication and consumer equipment. Waste Management \& Research, 31(10 Suppl), 3-16.

Charles R.G., Douglas P., Hallin I.L., Matthews I. and Liversage G. (2016), An investigation of trends in precious metal and copper content of RAM modules in WEEE: Implications for long term recycling potential, Waste Management.

Cui J. and Forssberg E. (2007), Characterization of shredded television scrap and implications for materials recovery, Waste Management, 27(3), 415-424. 
D'Adamo I., Rosa P. and Terzi S. (2016), Challenges in waste electrical and electronic equipment management: A profitability assessment in three European countries. Sustainability, 8(7), 633.

Dias P., Javimczik S., Benevit M., Veit H. and Bernardes A.M. (2016), Recycling WEEE: Extraction and concentration of silver from waste crystalline silicon photovoltaic modules, Waste Management, 57, 220-225.

Diaz F., Florez S. and Friedrich B. (2015). Mass flow analysis and metal losses by the degradation process of organic-containing WEEE scraps. Chemie Ingenieur Technik, 87(11), 1599-1608.

Directive 2012/19/EU of the European Parliament and of the Council of 4 July 2012 on waste electrical and electronic equipment (WEEE).

Duflou J.R., Seliger G., Kara S., Umeda Y., Ometto A. and Willems B. (2008), Efficiency and feasibility of product disassembly: a case-based study. CIRP Annals - Manufacturing Technology, 57, 583-600.

EC-European Commission. (2017). Communication from the Commission to the European Parliament, the Council, the European Economic and Social Committee and the Committee of the Regions on the 2017 List of Critical Raw Materials for the EU. Brussels 13.09.2017. available at http://eurlex.europa.eu/legal-content/EN/TXT/PDF/?uri= CELEX:52017DC0490\&from=EN (accessed 3.12.2017)

Gunn G. (Ed.). (2014). Critical Metals Handbook. John Wiley \& Sons.

Hageluken C. (2006), Improving metal returns and eco-efficiency in electronics recycling - a holistic approach for interface optimisation between pre-processing and integrated metals smelting and refining, Electronics and the Environment, International Symposium on (ISEE), Scottsdale, AZ, 2006.

Hobohm J., Kuchta K., Krüger O., van Wasen S. and Adam C. (2016), Optimized elemental analysis of fluorescence lamp shredder waste, Talanta, 147, 615-620.

Huisman J., Magalini F., Kuehr R., Maurer C., Ogilvie S., Poll J., Delgado C., Artim E., Szlezak J. and Stevels A.(2008), Review of Directive 2002/96 on Waste Electrical and Electronic Equipment (WEEE). Bonn.

Innocenzi V., De Michelis I., Ferella F. and Vegliò F. (2013), Recovery of yttrium from cathode ray tubes and lamps' fluorescent powders: experimental results and economic simulation, Waste management, 33(11), 2390-2396.

Işıldar A., Rene E.R., van Hullebusch E.D. and Lens P.N.L. (2017). Electronic waste as a secondary source of critical metals: Management and recovery technologies. Resources, Conservation and Recycling, Article in Press, https://doi.org/10.1016/j.resconrec.2017.07.031

Marra A., Cesaro A. and Belgiorno V. (2015), WEEE Mechanical Treatments: Recovery Effectiveness of Critical Materials, Proceedings of the 14th International Conference on Environmental Science and Technology. Rhodes, Greece, 3-5 September 2015.

Menad N., Guignot S., and van Houwelingen J.A. (2013), New characterisation method of electrical and electronic equipment wastes (WEEE). Waste Management, 33(3), 706713.

Meskers C. and Hagelüken C. (2009). The impact of different pre-processing routes on the metal recovery from PCs. URL: http://www.preciousmetals.umicore.com/PMR/Media/ escrap/impactOfDifferentPreprocessing. Pdf (assessed 2017).
Oliveira C.R.de, Bernardes A.M. and Gerbase A.E. (2012). Collection and recycling of electronic scrap: A worldwide overview and comparison with the Brazilian situation. Waste Management, 32(8), 1592-1610.

Savvilotidou V., Antoniou A. and Gidarakos E. (2017), Toxicity assessment and feasible recycling process for amorphous silicon and CIS waste photovoltaic panels, Waste Management, 59, 394-402.

Savvilotidou V., Hahladakis J.N. and Gidarakos E. (2014), Determination of toxic metals in discarded Liquid Crystal Displays (LCDs), Resources, Conservation and Recycling, 92, 108-115.

Savvilotidou V., Hahladakis J.N. and Gidarakos E. (2015), Leaching capacity of metals-metalloids and recovery of valuable materials from waste LCDs, Waste Management, 45, 314-324.

Sommer P., Rotter V.S. and Ueberschaar M. (2015), Battery related cobalt and REE flows in WEEE treatment, Waste Management, 45, 298-305.

Sun Z., Cao H., Xiao Y., Sietsma J., Jin W., Agterhuis H. and Yang, Y. (2016). Toward sustainability for recovery of critical metals from electronic waste: The hydrochemistry processes. ACS Sustainable Chemistry \& Engineering.

Tsamis A. and Coyne M. (2015). Recovery of Rare Earths from Electronic Wastes: An Opportunity for HIGH-Tech SMEs. Directorate General for Internal Policies Policy Department A: Economic and Scientific Policy.

Ueberschaar M., Geiping J., Zamzow M., Flamme S. and Rotter V.S. (2017a), Assessment of element-specific recycling efficiency in WEEE pre-processing, Resources, Conservation \& Recycling, 124, 25-41.

Ueberschaar M., Otto S.J. and Rotter V.S. (2017b), Challenges for critical raw material recovery from WEEE - The case study of gallium. Waste Management, 60, 534-545

Veit H.M., Diehl T.R., Salami A.P., Rodrigues J.D.S., Bernardes A.M. and Tenório J.A.S. (2005), Utilization of magnetic and electrostatic separation in the recycling of printed circuit boards scrap, Waste Management, 25(1), 67-74.

Wang X. and Gaustad G. (2012), Prioritizing material recovery for end-of-life printed circuit boards, Waste Management, 32(10), 1903-1913.

Yue-qing X. and Guo-jian L. (2004), The BATINTREC process for reclaiming used batteries, Waste Management, 24(4), 359363.

Zhang S. \& Forssberg E. (1998). Mechanical recycling of electronics scrap - the current status and prospects. Waste Management \& Research, 16(2), 119-128. 